\title{
Communicative Competence of Specialists of Different Professional Groups
}

\author{
Mikhail Bashkin \\ Candidate of Psychological Sciences, Associate Professor of Pedagogy and Pedagogical Psychology \\ Department at the Faculty of Psychology of P.G. Demidov Yaroslavl State University, Yaroslavl, Russia \\ 280784@list.ru
}

\author{
Doi:10.5901/mjss.2015.v6n6s5p193
}

\begin{abstract}
The article is devoted to the study of communicative competence of specialists. The research urgency is caused by insufficient development of this problem in the science of psychology, as well as the demands of practice indicating the need for a comprehensive research of communicative competence of the individual. Communicative competence of the specialist is understood by the author as a complicated multifunctional entity, having an integrative character and determining the effectiveness of professional activity. The author conducted an empirical research of communicative competence of specialists, representing such professions as doctors and lawyers. In the course of the study, it was founded the ratio of communicative tolerance and communicative control as the most important components of communicative competence of specialists. It is proved that the representatives of the legal profession are focused on the manifestation in their behavior communicative tolerance rather than health care workers. It is revealed that the level of communicative control of a specialist is not a decisive determinant while selecting a leading type of response to the interpersonal conflict. The author found that to a greater extent it is working experience which influences on the choice made by doctors and lawyers of a type of reaction in a conflict situation.
\end{abstract}

Keywords: competence, communicative competence, communication, specialist.

\section{Introduction}

A promising and important field of modern education is the formation of the individual ability to reach an agreement in terms of mutual activity. The particular relevance of this issue is currently under the conditions of multilevel education of Russia's signed up to the Bologna Process and the implementation of the competence approach in teaching (Bashkin, 2014). The most demanded are professionals with a high level of development of communicative competence. In this regard, the study of communicative competence of specialists in various fields of professional activity and the process of its formation is of a particular relevance.

\section{Literature Review}

One of the first attempts to explain human behavior in personal relationships based on the concept of "competence" was made by Anthony in the work entitled "Human Behavior in Organizations» (Antony, 1968). It should be noted that the term "competency" and "competence" are creative transformations of the English term competence. Competence comes from the Latin "competentis" - «to belong rightfully

Currently, the concept of "communicative competence" has a fairly wide range of definitions from its interpretation in the narrow sense (such as knowledge of cultural norms of communication, learning social behaviors) to broader definitions such as the communicative abilities of the individual to establish contact with the environment. Thus, at present in psychological science there is no single view on the definition and understanding of the content of communicative competence of the individual.

Our study is based on the definition of communicative competence which was proposed by V.I. Kashnitsky, defining it as "the set of cognitive, emotional and behavioral characteristics that are internal means of orientation and regulation of communicative actions targeted at establishing, maintaining and developing effective contacts with other people in a variety of interpersonal situations" (Kashnitsky, 2007).

According to L.A. Petrovskaya, the main component of communicative competence of personality is the operating unit, which includes knowledge, abilities, and communication skills (Petrovskaya, 1989). In a number of other researches it is noted that in addition to the operating unit in the structure of communicative competence, a system of internal resources must be presented including skills and qualities of (Lazarus \& Folkman, 1984), as well as attitude and value 
orientations (Semmer, 1993; Thomas, 1992).

Methodological and theoretical bases of our research are made by modern ideas underlying the competency approach (Karpov, 2005; Shadrikov, 2007); the position of the subject-activity approach to understanding the subject of communication activities (Abulkhanova-Slavskaya, 1980; Bederhanova, 2002); general psychological approaches to the definition of communicative competence (Kashapov, 2006; Petrovskaya, 1989); theoretical models of conflict (Antsupov, 2002; Grishina, 2000); modern concepts of professional identity formation (Mitin, 2003; Povarenkov, 2008).

\section{Research Methods}

In the framework of the present study, a comparative analysis of the communicative competence of specialists from two different professional groups - doctors and lawyers was conducted. Such selection of specialists in the professional affiliation is due, on the one hand, to practical needs, and, on the other hand, a weak elaboration in contemporary psychological research of a problem of communicative competence of members of the medical and legal spheres of professional activity.

The research was carried out on the basis of medical institution of Yaroslavl and Yaroslavl Regional Chamber of Attorneys. The study involved 84 people, including 50 doctors between the ages of 25 to 45 years $(25$ men and 25 women), 15 psychiatrists, 20 physicians, 15 surgeons with experience in these positions for at least 3-5 years with the qualification category, as well as 50 lawyers between the ages of 25 to 55 years ( 25 men and 25 women), with experience from 3 to 30 years.

The study was carried out in three stages. In the first phase (2014) was selected and tested a set of techniques aimed at the study of communicative competence of doctors, processing and interpretation of the results. In the second phase (2014-2015) especially communicative competence of lawyers was studied, by analogy with the study of communicative competence of doctors. In the third stage (2015) a comparative analysis of the structure of communicative competence of professionals of various professional affiliations (doctors and lawyers) was conducted.

At the stage of empirical research of communicative competence, the following techniques were used:

- Methods of diagnostics of general communicative tolerance of V.V. Boyko;

- Methods of diagnostics of communicative control of M. Schneider;

- Methods of diagnostics of communicative attitude of V.V. Boyko;

- Methods of diagnostics of responding to a conflict of M.M. Kashapova, T.G. Kiseleva.

\section{Results and Discussion}

Based on the results of theoretical research, we concluded that the basic quality of the structure of communicative competence of the experts, according to many scientists, is a communicative tolerance. It is an indicator of the attitude of the individual to the people, showing the degree of tolerance of unpleasant or unacceptable, in their view, mental states and actions of the partners in the interaction.

To study the connection of basic quality of communicative competence of the individual and the level of communicative control, all subjects were divided into three groups. The reason for the differentiation was the ranking of the results obtained by the method of diagnosis of a common communicative tolerance by polar groups.

The following groups of respondents were distinguished: 1) subjects with a low level of expression of the general communicative tolerance (GCT); 2) Subjects with moderate general communicative tolerance; 3) subjects with a high degree of communicative expression of the general tolerance (Table. 1).

Table 1. The degree of General Communicative Tolerance of Respondents

\begin{tabular}{|c|c|c|c|}
\hline & \multirow{2}{*}{ Total sample, \% } & \multicolumn{2}{|c|}{ Professional Group, \% } \\
\cline { 3 - 4 } & & Health-Care Workers, \% & Lawyers, $\%$ \\
\hline Degree of General Communicative Tolerance & 32,8 & 30 & 37,5 \\
\hline Low(0-44) & 46,9 & 42,5 & 54,2 \\
\hline Medium (45-89) & 20,3 & 27,5 & 8,3 \\
\hline High (99-135) & & 8 & \\
\hline
\end{tabular}

On the basis of correlation analysis (Pearson correlation coefficient) a positive relationship between levels of tolerance and communicative level of control $(r=0,57 ; p<0,05)$ was revealed that indicates that a specialist being tolerant to others 
is restrained in his emotional manifestations, he correlates his reaction to the behavior of other peopley; in communication he treats people sincerely and ingenuously.

There was also revealed a negative relationship between the level of general communicative tolerance with a negative index of communicative attitude $(r=-0,91 ; p<0,05)$ and such types of reacting to the interpersonal conflict such as "Aggression» $(r=-0,22 ; p<0$ 05) and "Care» $(r=-0,97 ; p<0,05)$. In addition a positive correlation with the type of communicative tolerance response to the conflict "Optimal solution» $(r=0,49 ; p<0,05)$ was discovered. .

Thus, tolerance as one of the basic characteristics of the communicative competence of specialists is connected with the desire of the individual to show restraint in their emotional and communicative forms and allows an individual to have a positive communicative attitude even before the moment of direct communication, and in a situation of conflict to focus on finding the most acceptable solution for both parties.

It is proved that tolerance is related to the age and experience of professional activity: positive correlations of level of general communicative tolerance both with the experience $(r=0,86 ; p<0,05)$, and with age $(r=0,44 ; p<0.05)$ of specialists are founded. Specialists with a low level of general communicative tolerance are found to have a significant correlation between the type of response to the conflict "optimal solution" and work experience $(r=0,99 ; p<0,05)$.

This connection may be due to the acquiring by a specialist in the course of his professional growth, the experience of solving interpersonal conflicts. We emphasize that in its psychological structure of interpersonal decisionmaking processes are integral, i.e. they are the products of the synthesis of the whole system of cognitive, emotional, volitional and motivational processes and are not reducible to their additive combination.

In our opinion, this pattern of interpersonal decision-making process can be extended to the organization of structure of communicative competence, as this competence is implemented in interpersonal interaction. Thus, the integration of the components of communicative competence, ensuring the realization of the optimal type of response to the conflict, leads to the emergence of new qualitative features of the competence of the individual in the course of professional formation, depending on experience and seniority.

To understand the peculiarities of the determination of the revealed relationship between the studied parameters the method of analysis of correlations was used (Table 2).

Table 2. Correlation Relationship of the Time of Professional Experience and the Type of Response to the Conflict, "Optimal Solution"

\begin{tabular}{|c|c|c|}
\hline \multirow{3}{*}{ 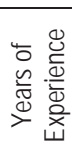 } & The Coefficients of Determination & Type of Response to the Conflict "The Optimal Solution" \\
\hline & $\eta y / x$ & 0,665 \\
\hline & $\eta x / y$ & 0,448 \\
\hline
\end{tabular}

Note: $\mathrm{x}$ - experience; $\mathrm{y}$ - value of indicator of the type of response to the conflict "Optimal solution"

As it can be seen from the data presented in the table, the coefficient of determination $\eta x / x$ statistically significantly different from $\eta x / y$. Therefore, according to the specialists' age it is possible to judge the severity of his behavior in response to the type of conflict "optimal solution". At the same time, according to the years of experience it is impossible to make an accurate conclusion about the dominant type of response to the conflict. It should be emphasized that the type of response to interpersonal conflict is a relatively stable character trait of an individual that largely determines the way of interacting in a conflict situation. In the M.M. Kashapov's research it is proved that the type of reaction is formed in the course of a human life and is based on his individual psychological characteristics (Kashapov, 2006). In addition, the formation of a leading type of reaction is influenced by the specificity of the professional activity of an individual.

The high level of communicative control is manifested in the constant implementation by the specialist a reflection of his psychological state and the ability to manage his emotions. At the same time, specialists with a high level of communicative control, experience considerable difficulty in spontaneity of expression, they do not like unpredictable situations. At the same time they are quite tolerant of his companion, allow to express different points of view, without bringing the situation to the conflict. A measure of the diversity of behavioral repertoire is due to the heterogeneity of his personal qualities as a determinant. High variability of behavior enables flexible rearrangements of strategies for the action of the individual in conflict interaction that contributes to finding the optimal variant of behavior in conflict situations.

To determine the significance of differences in the level of communicative control in the groups of specialists with low, medium and high levels of general communicative tolerance, U-test Mann - Whitney was used (Table. 3). 
Table 3. The Reliability of Differences in the Level of Communicative Control Groups of Specialists with Low, Medium and High Levels of General Communicative Tolerance

\begin{tabular}{|c|c|c|c|}
\hline & 1 and 2 Groups & 1 and 3 Groups & 2 and 3 Groups \\
\hline 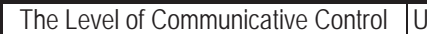 & 129,0 & 195,0 & 175,5 \\
\hline
\end{tabular}

Note: Group 1- a group of specialists with a low level of general communicative tolerance; Group 2 - a team of specialists with an average level of general communicative tolerance; Group 3 - a group of specialists with a high level of general communicative tolerance

The analysis of the data presented in Table 3 indicates that all subjects were significantly different from each other in terms of the communicative control.

It should be noted that a team of specialists with an average level of overall communicative tolerance there was found a significant correlation between the type of response to the conflict "optimal solution" and the age of the respondents $(r=-0,99 ; p<0,05)$. It is necessary to mention that the age, as a measure of the accumulation of human life experience, makes a certain invariant behavioral response to a situation of conflict, but a set of personality traits as a result provides a general behavioral repertoire. The more it is diverse, differentiated and labile in terms of changing situations, the better the behavior of the person, including also in the conflict.

A negative correlation between the index of level of communicative control and the type of response to the conflict "Care" from the specialists with a low and a high rate of general communicative tolerance $(r=-0,75 ; p<0,05)$ and $(r=$ $0,38 ; p<0,05)$ respectively is revealed. At the same time experts from the intermediate level of tolerance and a high level of communicative control have positive correlations with all types of response to the conflict.

It is proved that the maximum communicative control is observed in specialists with an average level of expression of communicative tolerance. At the same time it was found a connection between the level of communicative control and choice of a particular type of response in a conflict situation. In patients with severe communicative tolerance, as well as in patients with severe communicative intolerance, there is a tendency to emotional response in the situation of a conflict.

Analysis of the credibility of differences (by the U-Mann-Whitney test)allowed to make a conclusion that a group of health care workers, compared with lawyers, has less pronounced differences in the level of communicative control between subjects with low, medium and high levels of general communicative tolerance (Table. 4 ).

Table 4. The Credibility of Differences in the Level of Communicative Control in groups of Doctors and Lawyers with Low, Medium and High Levels of General Communicative Tolerance

\begin{tabular}{|l|l|c|c|c|}
\hline The Level of Communicative Control & \multirow{4}{*}{$\cup$} & 1 and 2 Groups & 1 and 3 Groups & 2 and 3 Groups \\
\cline { 1 - 3 } \cline { 3 - 5 } & \multirow{3}{*}{ Health-Care Workers } & 130,0 & 190,5 & 126,0 \\
\cline { 1 - 2 } & & 136,0 & 195,0 & 145,5 \\
\hline
\end{tabular}

Note: Group 1 - a group of specialists with a low level of general communicative tolerance; Group 2 - a team of specialists with an average level of general communicative tolerance; Group 3 - a group of experts with a high level of general communicative tolerance

Probably, the result is associated with the specificity of professional sectors of studied specialists.

The obtained significant positive correlation between the index of the general level of communicative tolerance and communicative control $(r=0,37 ; p>0,05)$ indicates that our assumption about the relationship between these two components of communicative competence in a group of doctors finds its confirmation.

This professional group also showed a significant negative correlation with indicators of communicative control with indicator "Categorical or conservatism in the evaluation of other people» $(r=-0,38 ; p>0,05)$ and "The desire to change, to re-educate a partner» $(r=-031 ; p>0.05)$. These data points out that the doctor who has a high level of communicative control, is characterized by the absence of categoricity in the evaluation and judgments, adequate perception of the partner in a dialogue and constructive attitude to him.

In the group of doctors there was also found a significant inverse relationship between the level of communicative control with indicators "Inability to hide or smooth the unpleasant feelings when faced with uncommunicative features of a partner» $(r=-0,34 ; p>0,05)$ and "inability to adapt to the character, habits and desires of others $»(r=-0,31 ; p>0,05)$. This suggests that if there is an immediate desire to be in communion and sincerely treat patients, medical doctors need to exercise restraint in emotional displays, to coordinate their response to the behavior and feelings of other people.

In the group of lawyers the level of communicative feedback control with the index "Rejection or lack of 
understanding of the other person's personality» $(r=-0,01 ; p>0,05)$ and a positive correlation with the index "Using myself as a standard in evaluating the behavior and way of thinking $»(r=0.32 ; p>0.05)$ was revealed.

The analysis of the significance of differences (by criterion of T-Student) led to the conclusion that lawyers have a significantly higher level of expression of the general communicative tolerance, compared with health-care specialists ( $p$ $<0,05)$. At the same time doctors have a higher level of communicative control $(p<0,05)$. Table 5 shows all the identified differences among representatives of these professional groups.

Table 5. The Credibility of Differences of Communicative Competence Indicators of Doctors and Lawyers on the Criterion of T Student

\begin{tabular}{|c|c|c|c|c|}
\hline Basic Features & $\begin{array}{c}\text { Health-Care } \\
\text { Workers }\end{array}$ & Lawyers & $\mathbf{T}$ & p \\
\hline The Level of Communicative Control & 6,5 & 4,5 & 3,15 & $p<0,05$ \\
\hline General Communicative Tolerance & 39,5 & 44,3 & 3,01 & $p<0,05$ \\
\hline The rejection or lack of understanding of another person's identity & 6,1 & 5,9 & 3,14 & $p<0,01$ \\
\hline Using oneself as a standard when assessing the behavior and way of thinking & 4,5 & 5,6 & 2,74 & $p<0,01$ \\
\hline Categoricity and conservatism in evaluation of other people & 5,7 & 5,8 & 1,70 & $p<0,05$ \\
\hline $\begin{array}{l}\text { The inability to hide or smooth the unpleasant feelings when faced with } \\
\text { uncommunicativeness of a partners }\end{array}$ & 5,8 & 6,6 & 2,01 & $p<0,05$ \\
\hline The desire to change and reeducate partners & 4,5 & 4,7 & 2,16 & $p<0,05$ \\
\hline The desire to fit partner for oneself, to make him "convenient" & 5,4 & 6,1 & 2,01 & $p<0,05$ \\
\hline The inability to forgive others mistakes, awkwardness, unintentionally caused trouble & 4,2 & 4,9 & 2,16 & $p<0,05$ \\
\hline Intolerance to physical and mental discomfort created by others & 3,0 & 3,2 & 2,01 & $p<0,05$ \\
\hline The inability to adapt to the character, habits and desires of others & 3,4 & 3,8 & 2,16 & $\mathrm{p}<0,05$ \\
\hline
\end{tabular}

In the study, we found that the doctor's professional experience as well as a lawyer has an impact on the specialist's choice of the type of response in interpersonal conflict. Doctors with experience of professional activity of at least ten years tend to use in conflict situations such responding as "Care", in comparison with their colleagues who have more work experience $(p<0,01)$.

It has been revealed that lawyers with experience of professional activity for more than ten years, are less likely to use such type of response as "Aggression" and focus more on the type of reaction "optimal solution" than their younger counterparts $(p<0,01)$.

\section{Conclusion}

Summarizing the results of the empirical research, we distinguish the following conclusions:

1. Communicative competence of a specialist is an integral psychological entity related to individual psychological and personal characteristics of a specialist, manifested in his behavior and being a basis to achieve the efficiency and effectiveness in his professional activities.

2. The level of total communicative tolerance and the level of communicative control of an individual are related. Maximum communicative control is observed in specialists with an average level of expression of communicative tolerance.

3. The representatives of the legal profession have a higher rate of communicative tolerance, compared to health care workers. At the same time doctors a higher level of communicative control.

4. Professional experience both of a doctor and a lawyer has an impact on the choice of the type of response in interpersonal conflict.

\section{Acknowledgements}

The work was carried out with the financial support of the project № 25.2356.2014K within the project part of the state task to scientific research of the Institute of Higher Education. 


\section{References}

Antony, G. (1968). Athos Behavior in Organizations. New Jersey: Prentice-Hall.

Bashkin, M.V. (2014). Formirovanie psihologicheski komfortnoj i bezopasnoj obrazovatel'noj sredy [Formation of psychologically comfortable and safe educational environment]. Yaroslavl: YarGU.

Kashapov, M. (2006). Osnovy konfliktologii (Fundamentals of Conflict). Yaroslavl: YarGU.

Kashnitsky, V.I. (2007). Kommunikativnaya kompetentnost' kak resurs sovladayushchego povedeniya lichnosti. Psihologiya sovladayushchego povedeniya: materialy mezhdunar. nauch.-prakt. konf. [Communicative competence as a personality controlling behaviour. Psychology of controlling behaviour: materials of intern. scientific and practical. conf.]. Kostroma: Nekrasov KGU, 201-202.

Lazarus, R.S., Folkman, S. (1984). Stress, Appraisal and Coping. N.Y.

Petrovskaya, L.A. (1989). Kompetentnost' v obshchenii. Social'no-psihologicheskij trening. [Competence in communication. Sociopsychological training]. Moskva.: MGU

Semmer, N., Udris, I. (1993). Bedeutung und Wirkung von Arbeit. In H. Schuler (Hrsg.), Lehrbuch Organisationspsychologie Bern: Huber, 133-165.

Thomas, K.W. (1992) Conflict and Negotiation. Processes in Organizations. In: Handbook of Industrial and Organizational Psychology, Vol. 3, 889-935. 